International Journal of Research in Nursing 1 (1): 8-16, 2010

ISSN 1949-0194

(C) 2010 Science Publications

\title{
Predictors of Home Health Care Service Use by Anglo American, Mexican American and South Korean Elders
}

\author{
${ }^{1}$ Myunghan Choi, ${ }^{2}$ Janice D. Crist, ${ }^{1}$ Marianne McCarthy and ${ }^{3}$ Seon Hae Woo \\ ${ }^{1}$ Arizona State University, College of Nursing and Health Innovation, Phoenix, AZ 85004 \\ ${ }^{2}$ University of Arizona, College of Nursing, Tucson, AZ 85721 \\ ${ }^{3}$ Gyeongsang National University, College of Nursing, Jinju-City, South Korea
}

\begin{abstract}
Problem statement: This study was designed to identify predictors of the use of home health care services by elders in different ethnic groups. Approach: A cross-sectional study was conducted with convenient sample of Anglo elders $(\mathrm{N}=57)$, Mexican American elders $(\mathrm{N}=56)$ and elders in South Korea $(\mathrm{N}=83)$. Hierarchical multiple regression analysis was conducted. Results: The need for home health care services was the significant predictor of home care service use for Anglo (Adjusted $\mathrm{R}^{2}=0.164 ; \mathrm{R}^{2}$ change $=0.176 ; \mathrm{F}$-change $\left.(1,56)=11.93 ; \mathrm{p}=0.001\right)$; service awareness and low education were significant predictors for Mexican American (Adjusted $R^{2}=0.332 ; R^{2}$ change $=0.068 ;$ F-change $(1,48)=5.22 ; \mathrm{p}=0.027)$. Service awareness and elders living alone were significant predictors for South Korean elders (Adjusted $\mathrm{R}^{2}=0.112 ; \mathrm{R}^{2}$ change $=0.050$; F-change $(1,80)=4.58 ; p=0.035)$. Conclusion: The results of the study suggested that effective interventions for home health care services should focus on elders' service awareness, low income and education and elders living alone to maximize the use of home health care services.
\end{abstract}

Key words: Use of home care service, Anglo American, Mexican American, South Korean elders

\section{INTRODUCTION}

Home health care is the fastest growing area in the health care system. Designed to assist elders and their family caregivers, home health services include skilled assessment, skilled teaching, substantial skilled treatments and support services (Calderon-Rosado et al., 2002; Hughes et al., 2000). As the number of elderly persons rises, the need for home health care is likely to grow significantly. In the US, for example, the number of people over 65 years old reached 36 million in 2007 (US Census Bureau, 2007). Over 14 million of this population has sensory, physical, mental, self-care and go-outside-home disabilities. Over 8 million of this population lives alone. The elderly population, in particular, is at high risk for falls and poor health status, resulting in a higher prevalence of chronic diseases including cardiovascular disease, chronic kidney disease, chronic obstructive pulmonary disease, hypertension and diabetes (Aranda et al., 2009; Elliott et al., 2009; Faul et al., 2009). These statistics point to a need for reliable predictors of home health care use.

Crist (2002) described a strong association between familism and home health care use. Familism describes the belief that family members are primarily responsible for care giving (Crist, 2005; Crist and Escandón-Dominguez, 2003). Further, children should meet their elder's needs in return for sacrifices made by their parents (Gelfand et al., 2001). Other factors potentially affecting home health care use include financial status, awareness of services and changing cultural mores (Crist et al., 2007).

In this study we look for predictors of home health care use among the elderly in two familiar cultures (Mexican American elders in the US and Korean elders in Korea) and one non-familiar culture (AngloAmerican elders in the US). While Mexican American elders and Korean elders may be geographically distant, these two populations are similar in the way they conceive of family care giving roles (Crist et al., 2007). In addition, Korean society is becoming increasingly westernized; women are becoming more financially independent and individualistic, perhaps leading to changes in views toward familial obligations (Kim and Yang, 2005). We felt that examining these threes would provide us with a diverse, yet comparable set of data from which to develop the predictors.

Purpose: The purpose of the study was to identify predictors of home care service by three different ethnic

Corresponding Author: Myunghan Choi, Arizona State University, College of Nursing and Health Innovation, Phoenix, AZ 85004 
groups, examining relationships of the services to cultural, contextual and sociostructural factors to better serve home health care. Identifying factors is essential to maximizing the use of home health care services and minimizing disparities in their use among different ethnic groups. We therefore considered variations in cultural, contextual and sociostructural factors in the use of home health care services.

Cultural, contextual and sociostructural factors: The principle of familism describes an emphasis on traditional values and asserts that family members are primarily responsible for care-giving and the family's well-being (Crist, 2002; 2005; Crist and EscandónDominguez, 2003). Familism describes a belief that elders' needs should be met by their children in return for sacrifices made by them as parents (Gelfand et al., 2001). In general, Mexican American family members follow allocentric values or collectivist motivations to provide care for one another, putting the group ahead of the self. This is culturally distinct from the more individualistic paradigm of Anglo families. The need for home health care services is predicated on the elder's perception that home health care services are necessary. The recognition of the need for services can be viewed as "a consensus of beliefs" constructed as part of a group or culturally defined value (Duffy and Cunningham, 1996).

Health status refers to the elder's level of health problems. Acute or chronic declines in the elder's condition may increase the possibility that the elder will use home health care services (Pol et al., 2002). In previous studies, factors such as "hospitalized within the past year" have been proxies for health status (Burnette and Mui, 1995). Functional status is the elder's level of independence in performing Activities of Daily Living (ADLs) and Instrumental Activities of Daily Living (IADLs) and has often been reported as the strongest predictor of use by Kadushin (2004), Mexican American (Burnette and Mui, 1995) and Korean elders who have various diagnoses (Kim, 2007). Service awareness refers to an understanding that home health care services exist and an awareness of how to access them (Crist et al., 2007). Awareness that services exist is distinct from actually accessing and using them. Financial status is the elder's ability to pay for home health care services. Having health insurance increases the likelihood that elders will use home health care services (Gure et al., 2009).

Health insurance: In the United States, $71 \%$ of Latino elders with serious chronic conditions report problems affording their care. This problem is compounded because Mexican American elders in general have more chronic illnesses, which often occur before they reach the age of 65 . Yet working elders who live below federal poverty guidelines may not qualify for funding in programs (e.g., Medicare-managed organizations) that require a flat per-capita fee for providing health care for each beneficiary enrolled in the plan (CMM, 2008). Funding in the United States may come from Medicare, Medicaid, or long-term care and other health insurance plans. Eligibility for Medicare requires that the patient is 65 years old or older, is a US citizen and has contributed to the Social Security System. Other funding sources for home health care services are programs under the Older Americans Act for lowincome people aged 60 and older.

In Korea, home health care services provided by hospitals are comprehensive. Government services are intended for both impoverished elders and rural elders who live far from hospitals. Korean elders who are eligible only for home health care services through the government receive the minimal coverage called Boho (Crist et al., 2007). If public funding is not available, private pay for home health care services is closely tied to income. Fee-sliding scales based on income level are not available through private pay.

\section{MATERIALS AND METHODS}

Study design: A cross-sectional study was undertaken to compare the use of home health care services by different ethnic groups. This study design was chosen because we were interested in the same variables at the same point in time to identify predictors of use of home health care services based on significant correlations among variables interested in our study.

Human subjects protection: The University of Arizona Human Subjects Committee approved the US study in 2002. We recruited Anglo elders and Mexican American elders. Participants were informed about participation rules, confidentiality guidelines and data collection and storage. The Anglo principal investigator and a bicultural/bilingual research associate provided assistance with completing 10 page Spanish and English questionnaires. Elders were given a $\$ 5.00$ gift for completing the questionnaires. In Korea, the study procedures were similar. The study was approved by the Gyeongsang National University Human Subjects Committee. Two trained research associates provided assistance with completing the questionnaires. Elders in Korea did not receive a gift for completing the questionnaires.

Settings and sample: Study sites were a southwestern city (population 946,362 in 2005) in the United States and a medium-sized city (population 340,816 in 2006) 
in Korea. In the US city, data were collected at senior centers, churches and neighborhood associations. In the Korean city, data were collected at churches; neighborhood associations, nursing homes and "Noinjung," senior centers where elders get together to chat and participate in activities during the course of daily life. The elders living in the United States and Korea were a convenience sample and were included in the study if they were (a) 55 years of age and older and (b) community-dwelling.

Data analysis: A total of 196 elders, including Anglo American $(\mathrm{N}=57)$, Mexican American $(\mathrm{N}=56)$ and Korean elders $(\mathrm{N}=83)$, participated in the study. The sample size was drawn using power analysis based on a previous study (Crist et al., 2007). For the given effect size (population correlation of $0.78 \mathrm{Vs} 0.46$ based on Anglo American and Mexican American elders), alpha 0.05 ( 2 tailed) and power 0.8 , the sample size of Korean elders $>60$ was sufficient to adequately identify predictors of the use of home health care services. Power analysis was computed using Fisher $\mathrm{Z}$ approximation. The software program used was Power and Precision (version 2.0).

Internal consistency of the instruments was assessed using Cronbach's alpha. Chi-square tests and ANOVA were conducted to examine demographic differences among the three ethnic groups. Correlation coefficients were used to determine the strength, association and direction of linear relationships among variables in the model (Robinson, 2001). We conducted hierarchical multiple regression to compare betas for the purpose of assessing the importance of sets of independent variables on a dependent variable (use of home health service) by different ethnic groups. Rsquare, R-square change and residual analysis were computed to explain the percent of the variance in the use of home health care services explained by sets of independent variables, spot additional explanatory importance given the common variance compared to previous R-square and identify outliers and patterns of errors. All data analyses were conducted using SPSS (version 17).

Measures: Several instruments were used to assess the variables explored in the study. For the US study, measures were selected to ensure language and conceptual equivalence for the Spanish version. A panel of language experts reviewed all measures (Jones et al., 2006). In Korea, the Korean investigator and a bilingual research expert translated the instruments, focusing on equal familiarity in both sources (e.g., contextual factors) of the target population and items common to both cultures (e.g., financial status). Familism was originally measured with a 14 item self-report questionnaire derived from Sabogal et al. (1987) with Likert-style responses, ranging from 1 (strongly disagree) to 5 (strongly agree); it has good reliability report $(\mathrm{r}=0.83)$. We found that 2 items in the familism questionnaire would be redundant for Korean elders. We found that the item, "When one has problems, one can count on the help of relatives" was redundant with the item, "One can count on help from one's relatives to solve most problems". These questions did not describe the subtle differences apparent in the Spanish and English versions. For the Korean version, we retained the former item and deleted the latter item from all ethnic groups to avoid the inflation of Cronbach's alpha. Therefore, for all groups we used 13 items concerning familism to measure the importance of family, family support and family conflict in the use of home health care services.

We measured the need for services using an item in the questionnaire by asking "Yes" or "No." We measured health status using the Older Americans Resources and Services (OARS) Multidimensional Functional Assessment of Older Adults (OMFAQ) and "Physical Health" scale. OMFAQ is a 27-item selfreport measure with Likert-style responses, ranging from 1 (strongly disagree) to 5 (strongly agree). The lower the score, the higher the health status. Cronbach's alpha was 0.82 . We measured functional status using the ADL subscale of the OMFAQ (Fillenbaum, 1988). The subscale was a self-report measure consisting of 5 items of functional status. The lower the score, the higher the functional status. Cronbach's alpha was 0.89 . We measured service awareness by totaling the scores of 2 items: "Knowledge of existing services" and "potential to use services". We measured financial status using the "economic resources" subscale of the OMFAQ. The higher the score is, the more money is available. Cronbach's alpha was 0.68 . We measured the use of home health care services with a "Yes" or "No" question about whether home health care services were being used or had ever been used.

\section{RESULTS}

Demographics: The average age of the Anglo elders was 77.6 years, significantly higher than the average age of the Mexican American elders (70.4 years) and the Korean elders (70.4 years; $F=17.83$, df $=2$, $\mathrm{p}=0.000)$. Anglo and Korean elders' years of education completed were higher than the years completed by Mexican American elders ( $\mathrm{F}=118.71$; $\mathrm{df}=2 ; \mathrm{p}=0.000)$. The majority of Korean elders $(85.5 \%)$ were married and living with their spouses; this was higher than for Anglos (31.6\%) and Mexican American elders $\left(29.6 \% ; \chi^{2}=59.56 ; \mathrm{df}=2 ; \mathrm{p}=0.000\right)$. 
Intl. J. Rec. Nursing 1 (1): 8-16, 2010

Table 1: Demographics of Anglo, Mexican American and South Korean elders

\begin{tabular}{|c|c|c|c|}
\hline Variable & Anglo American $\mathrm{n}=57(\%)$ & Mexican American $\mathrm{n}=56(\%)$ & South Korean $\mathrm{n}=83(\%)$ \\
\hline \multicolumn{4}{|l|}{ Gender } \\
\hline Male & $11(19.3)$ & $11(19.6)$ & $28(33.7)$ \\
\hline \multicolumn{2}{|c|}{$\chi^{2}=5.85 ; \mathrm{df}=2 ; \mathrm{p}=0.053$} & $45(80.4)$ & $55(66.3)$ \\
\hline Average age & $77.6 \pm 8.3$ & $\begin{array}{l}85 ; \mathrm{df}=2 ; \mathrm{p}=0.053 \\
70.4 \pm 7.1 \\
83 ; \mathrm{df}=2 ; \mathrm{p}=0.000\end{array}$ & $70.4 \pm 4.8$ \\
\hline Education & $13.21 \pm 2.57$ & $\mathrm{~F}=118.71 ; \mathrm{df}=2 ; \mathrm{p}=0.000$ & $13.26 \pm 5.18$ \\
\hline \multicolumn{4}{|l|}{ Marital status } \\
\hline Single, widowed, separated, or divorced & $39(68.4)$ & $40(71.4)$ & $12(14.5)$ \\
\hline \multirow{2}{*}{\multicolumn{4}{|c|}{$\chi^{2}=59.56 ; \mathrm{df}=2 ; \mathrm{p}=0.000$}} \\
\hline & & & \\
\hline Hypertension & $17(19.3)$ & $13(23.2)$ & $26(31.3)$ \\
\hline Diabetes & $3(5.3)$ & $13(23.2)$ & $10(12.0)$ \\
\hline Heart disease & $17(29.8)$ & $13(23.2)$ & $14(16.9)$ \\
\hline Arthritis & $11(19.3)$ & $16(28.6)$ & $23(27.7)$ \\
\hline Other & $13(22.8)$ & $13(23.2)$ & $18(21.7)$ \\
\hline \multirow{2}{*}{\multicolumn{4}{|c|}{$\chi^{2}=31.79 ; \mathrm{df}=10 ; \mathrm{p}=0.000$}} \\
\hline & & & \\
\hline Financial status & & & \\
\hline Not enough money to pay bills & $2(3.5)$ & $10(17.9)$ & $14(16.9)$ \\
\hline Barely making ends meet & $5(8.8)$ & $29(51.8)$ & $40(48.2)$ \\
\hline Have enough money to pay bills & $38(66.7)$ & 11 (19.6) & $28(33.7)$ \\
\hline Have enough money for everything & $12(21.1)$ & $4(7.1)$ & $1(1.2)$ \\
\hline \multicolumn{4}{|c|}{$\chi^{2}=53.48 ; \mathrm{df}=6 ; \mathrm{p}=0.000$} \\
\hline Yes & $52(91.2)$ & $52(92.9)$ & $62(74.7)$ \\
\hline No & $5(8.8)$ & $4(7.1)$ & $21(25.3)$ \\
\hline \multicolumn{4}{|c|}{$\chi^{2}=11.11 ; \mathrm{df}=2 ; \mathrm{p}=0.004$} \\
\hline
\end{tabular}

Korean elders had disproportionately high rates of hypertension (31.3\%) compared with Anglos (who had disproportionately high rates of heart disease: 29.8\%) and Mexican American elders (who had disproportionately high rates of arthritis: $28.6 \%$; $\left.\chi^{2}=31.79 ; \mathrm{df}=10 ; \mathrm{p}=0.000\right)$. Over $12 \%(12.3 \%)$ of Anglo elders, $69.7 \%$ of Mexican American elders and $65.1 \%$ of Korean elders reported that they barely made ends meet or that they did not have enough money to pay bills $\left(\chi^{2}=53.48 ; \mathrm{df}=6 ; \mathrm{p}=0.000\right)$. Over $90 \%$ (91.2\%) of Anglo elders, $92.9 \%$ of Mexican American elders and $74.7 \%$ of Korean elders had health insurance $\left(\chi^{2}=11.11 ; \mathrm{df}=2 ; \mathrm{p}=0.004 ;\right.$ Table 1$)$.

Reliability: The Cronbach's alpha of the familism questionnaire used for this study was 0.86 for Anglo, 0.84 for Mexican American and 0.83 for Korean elders. The Cronbach's alpha of health status using the OMFAQ was 0.76 for Anglo, 0.93 for Mexican American and 0.89 for Korean elders. The Cronbach's alpha of the functional status subscale using the OMFAQ was 0.65 for Anglo, 0.74 for Mexican American and 0.68 for Korean elders. The Cronbach's alpha of the service awareness questionnaire was 0.73 for Anglo, 0.62 for Mexican American and 0.43 for Korean elders. Overall, items on each scale demonstrated an adequate internal consistency of items, except for service awareness for Korean elders. For Korean elders, the low internal consistency $(\alpha=0.43$ ) of service awareness could be due to 12 missing data points across the items.

Use of home health care services by Anglo American Elders: For Anglo elders, use of home health care services was significantly correlated with need $(r=0.477$; $\mathrm{p}<0.01)$, functional status $(\mathrm{r}=0.337, \mathrm{p}<0.05)$ and service awareness $(r=0.738, p<0.01)$, indicating that Anglo elders used home health care services when they perceived the need for the services, when their functional status declined and when they were aware of home health care services available. There were significant intercorrelations between need and functional status $(r=0.313, p<0.05)$ and need and health status $(r=0.308$, $\mathrm{p}<0.05$ ), indicating that the need for home health care services depended on their functional status and current health status (Table 2). For hierarchical multiple linear regression, we first included demographic variables including age, education, marital status, gender and number of children as the first set of independent variables followed by cultural variables (familism, need for home health services), contextual variables (health status, functional status, service awareness) and sociostructural variables (financial status, health insurance). $R^{2}, R^{2}$ change and residuals were computed. Surprisingly, the need for home health care services was the only predictor of the use of home health care services among Anglo Americans $(\beta=0.419, \mathrm{t}=3.455$, $\mathrm{p}=0.001)$, demonstrating $16.4 \%$ of the variance was explained by the model (Adjusted $\mathrm{R}^{2}=0.164, \mathrm{~F}=11.93$, 
Intl. J. Rec. Nursing 1 (1): 8-16, 2010

Table 2: Relationships among Anglo elders' home care services use and specific factors

\begin{tabular}{|c|c|c|c|c|c|c|c|}
\hline & \multicolumn{2}{|c|}{ Cultural/ethnic } & \multicolumn{3}{|c|}{ Contextual } & \multirow{2}{*}{$\begin{array}{l}\text { Socio- structural } \\
\text { Financial status }\end{array}$} & \multirow{2}{*}{$\begin{array}{l}\text { Outcome } \\
\text { use }\end{array}$} \\
\hline & Familism & Need & Health status & Functional status & Service awareness & & \\
\hline \multicolumn{8}{|l|}{ Cultural/ethnic } \\
\hline Familism & 1.000 & & & & & & \\
\hline Need & 0.000 & 1.000 & & & & & \\
\hline \multicolumn{8}{|l|}{ Contextual } \\
\hline Health status & 0.113 & $0.308^{*}$ & 1.000 & & & & \\
\hline Functional status & -0.115 & $0.313^{*}$ & $0.560 * *$ & 1.000 & & & \\
\hline Service awareness & -0.124 & -0.122 & 0.043 & 0.021 & 1.000 & & \\
\hline \multicolumn{8}{|l|}{ Social structural } \\
\hline Financial status & $0.335^{* *}$ & 0.000 & 0.100 & 0.138 & 0.021 & 1.000 & \\
\hline \multicolumn{8}{|l|}{ Outcome } \\
\hline Use & 0.077 & $0.477 * *$ & 0.171 & $0.337 *$ & $0.738 * *$ & -0.128 & 1 \\
\hline \multicolumn{8}{|c|}{ *: Correlation is significant at the 0.05 level (2-tailed); $* *:$ Correlation is significant at the 0.01 level (2-tailed) } \\
\hline & \multicolumn{2}{|c|}{ Cultural/ethnic } & \multicolumn{3}{|c|}{ Contextual } & \multirow{2}{*}{$\begin{array}{l}\text { Socio- structural } \\
\text { Financial status }\end{array}$} & \multirow{2}{*}{$\begin{array}{l}\text { Outcome } \\
\text { use }\end{array}$} \\
\hline & Familism & Need & Health status & Functionalstatus & Service awareness & & \\
\hline \multicolumn{8}{|l|}{ Cultural/ethnic } \\
\hline Familism & 1.000 & & & & & & \\
\hline Need & 0.021 & 1.000 & & & & & \\
\hline \multicolumn{8}{|l|}{ Contextual } \\
\hline Health status & 0.076 & 0.084 & 1.000 & & & & \\
\hline Functional Status & -0.031 & $0.499 * *$ & $0.269 *$ & 1.000 & & & \\
\hline Service Awareness & $0.305^{*}$ & -0.219 & $0.280^{*}$ & -0.028 & 1.000 & & \\
\hline \multicolumn{8}{|l|}{ Social structural } \\
\hline Financial status & 0.109 & 0.000 & -0.068 & 0.066 & -0.028 & 1.000 & \\
\hline \multicolumn{8}{|l|}{ Outcome } \\
\hline Use & 0.043 & $0.270 *$ & $0.400^{* *}$ & $0.341 *$ & $0.424 * *$ & -0.255 & 1 \\
\hline
\end{tabular}

*: Correlation is significant at the 0.05 level (2-tailed); **: Correlation is significant at the 0.01 level (2-tailed)

Table 4: Relationships among South Korean elders' home care services use and specific factors

\begin{tabular}{|c|c|c|c|c|c|c|c|}
\hline & \multicolumn{2}{|c|}{ Cultural/ethnic } & \multicolumn{3}{|c|}{ Contextual } & \multirow{2}{*}{$\begin{array}{l}\text { Socio-structural } \\
\text { Financial status }\end{array}$} & \multirow{2}{*}{$\begin{array}{l}\text { Outcome } \\
\text { Use }\end{array}$} \\
\hline & Familism & Need & Health status & Functional status & Service awareness & & \\
\hline \multicolumn{8}{|l|}{ Cultural } \\
\hline Familism & 1.000 & & & & & & \\
\hline Need & -0.047 & 1.000 & & & & & \\
\hline \multicolumn{8}{|l|}{ Contextual } \\
\hline Health status & 0.444 & 0.197 & 1.000 & & & & \\
\hline Functional status & 0.037 & 0.061 & 0.012 & 1.000 & & & \\
\hline Service awareness & -0.013 & $0.235^{*}$ & $0.228 *$ & 0.070 & 1.000 & & \\
\hline Socio-structional & & & & & & & \\
\hline $\begin{array}{l}\text { Financial status } \\
\text { OUTCOME }\end{array}$ & 0.105 & 0.209 & 0.209 & 0.080 & 0.214 & 1.000 & \\
\hline Use & 0.105 & 0.005 & 0.014 & 0.130 & $0.290 * *$ & 0.074 & 1 \\
\hline
\end{tabular}

* Correlation is significant at the 0.05 level (2-tailed) $\quad * *$ Correlation is significant at the 0.01 level (2-tailed)

$\mathrm{p}=0.001)$. The $\mathrm{R}^{2}$ change of $17.6 \%$ was significant $(\mathrm{p}$ $=0.001)$. The range of standard residual was -1.257 to 2.411 (standard predicted value ranged from -0.638 to 1.540) (Table 5).

Use of home health care services by Mexican American Elders: For Mexican American elders, the use of home health care services significantly correlated with need $(\mathrm{r}=0.270, \mathrm{p}<0.05)$, health status $(\mathrm{r}=0.400$, $\mathrm{p}<0.01)$, functional status $(\mathrm{r}=0.341, \mathrm{p}<0.5)$ and service awareness $(\mathrm{r}=0.424, \mathrm{p}<0.01)$. There were also significant intercorrelations between need and functional status $(r=0.499 ; \mathrm{p}<0.01)$ and familism and financial status $(\mathrm{r}=0.335, \mathrm{p}<0.01)$. This may reflect the protective factor of having family members who are helping the elder maintain autonomy in the presence of financial independence (Table 3). The significant results are consistent with a study demonstrating that health problems increase perceptions of need for home health care services (Wallace et al., 1998). The hierarchical multiple regression indicated that service awareness $(\beta=0.342, \mathrm{t}=2.293, \mathrm{p}=0.027)$, low income $(\beta=-0.299$, 
Intl. J. Rec. Nursing 1 (1): 8-16, 2010

Table 5: Regression predicting the use of home health care services by ethnicity

\begin{tabular}{|c|c|c|c|c|}
\hline \multirow{2}{*}{ Model } & & \multicolumn{3}{|c|}{ Standardized coefficients } \\
\hline & & $(\beta)$ & $\mathrm{t}$ & $\mathrm{p}$-value \\
\hline \multicolumn{5}{|c|}{ Anglo American elders } \\
\hline Need & $\begin{array}{l}\mathrm{F}=11.973 ; \text { Adjusted } \mathrm{R}^{2}=0.164 ; \mathrm{p}=0.001 \\
\mathrm{R}^{2} \text { change }=0.176 ; \mathrm{F} \text {-change }(1,56)=11.93 ; \mathrm{p}=0.001 \\
\text { Standardized residual: }-1.257 \sim 2.411 \\
\text { Standardized predicted value: }-0.638 \sim 1.540\end{array}$ & 0.419 & 3.455 & 0.001 \\
\hline \multicolumn{5}{|c|}{ Mexican American elders } \\
\hline Service awareness & $\begin{array}{l}F=11.525 ; \text { Adjusted } R^{2}=0.171 ; p=0.001 \\
R^{2} \text { change }=0.187 ; F \text {-change }(1,50)=11.53 ; p=0.001\end{array}$ & 0.433 & 3.395 & 0.001 \\
\hline Service awareness & & 0.369 & 3.043 & 0.004 \\
\hline Financial status & $\begin{array}{l}F=10.633 ; \text { Adjusted } R^{2}=0.274 ; p=0.000 \\
R^{2} \text { change }=0.115 ; \text { F-change }(1,49)=8.10 ; p=0.006\end{array}$ & -0.345 & -2.847 & 0.006 \\
\hline Service awareness & & 0.342 & 2.923 & 0.027 \\
\hline Financial status & & -0.299 & -2.521 & 0.015 \\
\hline \multirow[t]{5}{*}{ Education level } & & -0.268 & -2.285 & 0.027 \\
\hline & $\mathrm{F}=9.439 ;$ Adjusted $\mathrm{R}^{2}=0.332 ; \mathrm{p}=0.000$ & & & \\
\hline & $\mathrm{R}^{2}$ change $=0.068 ; \mathrm{F}$-change $(1,48)=5.22 ; \mathrm{p}=0.027$ & & & \\
\hline & Standardized residual: $-2.011 \sim 1.807$ & & & \\
\hline & Standardized predicted value: $-2.470 \sim 2.589$ & & & \\
\hline \multicolumn{5}{|c|}{ South Korean elders } \\
\hline \multirow[t]{2}{*}{ Service awareness } & & 0.290 & 2.730 & 0.008 \\
\hline & $\begin{array}{l}F=7.455 ; \text { Adjusted } R^{2}=0.0734 ; p=0.008 \\
R^{2} \text { change }=0.084 ; F-\text { change }(1,81)=7.45 ; p=0.008\end{array}$ & & & \\
\hline \multirow{6}{*}{$\begin{array}{l}\text { Service awareness } \\
\text { Marital status }\end{array}$} & & 0.322 & 3.066 & 0.003 \\
\hline & & -0.225 & -2.142 & 0.035 \\
\hline & $\mathrm{F}=6.187 ;$ Adjusted $\mathrm{R}^{2}=0.112 ; \mathrm{p}=0.003$ & & & \\
\hline & $\mathrm{R}^{2}$ change $=0.050 ; \mathrm{F}$-change $(1,80)=4.58 ; \mathrm{p}=0.035$ & & & \\
\hline & Standardized residual: $-1.180 \sim 4.099$ & & & \\
\hline & Standardized predicted value: $-0.689 \sim 2.166$ & & & \\
\hline
\end{tabular}

$\mathrm{t}=-2.521, \mathrm{p}=0.015)$ and low education $(\beta=-0.268$, $\mathrm{t}=-2.285, \mathrm{p}=0.027$ ) were significant predictors of home care service use, indicating that the more the elders were aware of available home health care services, the more they tended to use home health care services; Mexican American elderly persons with lower income and education tended to use home health care services more than those with higher income and education levels. The final model explained $33.2 \%$ of the variance (Adjusted $\mathrm{R}^{2}=0.332, \mathrm{~F}=9.439$ and $\mathrm{p}=0.000$ ). The $\mathrm{R}^{2}$ change of $6.8 \%$ was significant at the $\mathrm{p}$-value of 0.027 . The range of standard residual was -2.011 to 1.807 (standard predicted value ranged from -2.470 to 2.589) (Table 5).

Use of home health care services by Korean elders: For Korean elders, the only factor that significantly correlated with the use of home health care services was service awareness $(r=0.290, p<0.01)$. There was no significant intercorrelation between the need for home health care services and either health status or functional status. Service awareness, however, was significantly correlated with the need for home health care services $(r=0.235, \mathrm{p}<0.05$; Table 4$)$. We also compared this result using linear regression analysis with conditional stepwise forward. The same predictors were included in the model. Service awareness $(\beta=0.322, \mathrm{t}=3.066, \mathrm{p}=0.003)$ and marital status $(\beta=-0.225, t=-2.142, p=0.035)$ were the significant predictors of the use of home health care services among Korean elders. Korean elders chose the use of home health care services when they were aware of home health care services available and when they did not have spouses or partners to take care of them. The final model demonstrated that $11.2 \%$ of the variance was properly explained by the predictors $(\mathrm{F}=6.187$, Adjusted $\left.\mathrm{R}^{2}=0.112, \mathrm{p}=0.003\right)$. The $\mathrm{R}$-square change of $5.0 \%$ was significant at the p-value of 0.035 . The range of standard residual was -1.108 to 4.099 (standard predicted value ranged from -0.689 to 2.166 ) (Table 5).

\section{DISCUSSION}

The study demonstrated that familism was not a significant predictor of the use of home health care services for elders across ethnic groups. This result 
could prompt a reexamination of the role of familism, formerly reported as being strongly associated with the use of home health care services among Mexican American and Korean elders who are used to familycentered caregiving. One explanation for the findings revealed in this study is the growing individualism in the family setting. The unexpected non-significance between familism and use may be related to the elders' changing expectations. Rapid growth in the number of people of advanced age has caused significant alterations in the social, economic and physical environment of many Korean communities. The beliefs and values of the younger generation have evolved from traditional beliefs, including the belief that children will care for their parents. Although most elders value family ties, harmony and traditional beliefs, many elders now avoid seeking help because they perceive that their younger family members consider them to be a burden to their family (Choi, 2004).

For Anglo American elders, the only significant predictor of home health service use was the need for home health care services with significant R-square change (17.6\%). This finding demonstrates that as health-related problems increase, so does the assistance required for ADLs, leading to an increased need for home health care services.

Service awareness was a significant predictor of the use of home health care services among Mexican American elders. This result may also suggest that elders took an active role in finding out more about services as they developed more problems (Crist et al., 2006). Mexican American elders who did not subscribe to traditional familial values that family members are primarily responsible for care giving were more likely to aware of home health care services. Lower income and education levels in Mexican American elders were also significant predictors of the use of home health care. This result may be due to a lack of informal caregiver resources (e.g., family or spouses) to make ends meet in their daily lives. Mexican American elders who have financial resources and higher education levels are more likely to use formal services such as those provided by a home health care nurse (FCA, 2007). The final model of the Mexican American elder group was well explained by predictors compared with other two ethnic groups, demonstrating that there was a smaller range of residuals than predicted values.

For Korean elders, service awareness and marital status were significant predictors of home health service use. Korean elders not married or not living with their partners were more likely to use home health care services than their married counterparts. This finding is likely related to assumption that unmarried elders do not have informal caregivers, may lack the option of family-centered care giving, or have less family interaction than married elders (Tennstedt et al., 1990). In contrast to Anglo American and Mexican American elders, Korean elders may tend to rely more on their spouses when they need to be taken care of simply because the spouses are there. The low R-square change of $5.0 \%$ in the final model indicated that there was a wide range of residuals compared with those in the two other ethnic groups. This indicates that the value of predictors left unexplained are still large and may need to be identified in future studies.

A consideration in interpreting the study is that traditional cultural norms have not exerted much influence on decisions about the use of home health care services. Regardless of resource availability, many Mexican American and Korean elders tend to be more concerned with the health care needs of other family members than with their own needs. Taking care of their spouses is an important cultural norm that influences the elders' lack of home care service use (Choi, 2004; Choi, 1993).

Limitations and research implications: Because the US samples were drawn mainly from senior meal sites, sampling and recruitment procedures may have resulted in a Mexican American sample that was more acculturated, more connected with community health services and represented fewer marginalized elders. Efforts should be made to recruit more socially isolated and less healthy elders in future studies. Methodological issues including selection, sampling and measurement bias might limit the generalizability of the result.

\section{CONCLUSION}

The purpose of the study was to identify predictors of home health service use using hierarchical multiple regression analysis by different ethnic groups. Awareness of home health care services was a common predictor for Mexican American and Korean elders. Optimized interventions designed to increase the use of home health services for different ethnic groups would benefit from taking into account the importance of maximizing awareness of those services in the use of home health care services. The interventions can include cultural awareness and competency in designing community outreach programs. Education and counseling for family and elders, marketing that targets elders living alone or elders who have low income and education levels may ensure equity in 
healthcare delivery, especially for elders who are not accustomed to having home health care services available.

\section{ACKNOWLEDGEMENT}

Many thanks to Nancy Moore, Editor at ASU, CONHI for her thorough review and Ron Saito, PhD for his qualitative critique of the manuscript and support. Thanks to the ENCASA Community Advisory Council and thanks to Dr. Linda R. Phillips, PhD, RN, FAAN, who was the PI of the University of Arizona, College of Nursing, NRSA T32, which funded this research.

\section{REFERENCES}

Aranda, M.P. and B.G. Knight, 1999. The influence of ethnicity and culture on the caregiver stress and coping process: A sociocultural review and analysis. Gerontologist, 37: 342-354. PMID: 9203758

Aranda, R., L. Alquezar, M. Terrer and M. Botaya, 2009. Chronic diseases and functional deterioration in activities of daily living in community-dwelling elders. Rev Espgeriatr Gerontol, 44: 244-250. PMID: 19647894

Burnette, D. and A.C. Mui, 1995. In-home and community-based service utilization by three groups of elderly Hispanics: A national perspective. Soc. Work Res., 19: 197-206. PMID: 10152599

Calderon-Rosado, V., A. Morrill, B.H. Chang and S. Tennstedt, 2002. Service utilization among disabled Puerto Rican elders and their caregivers: Does acculturation play a role? J. Aging Health, 14: 3-23. DOI: $10.1177 / 089826430201400101$

Centers for Medicare and Medicaid Services (CMM), 2008. Medicare home health agency utilization and expenditure data by race and age groupcalendar year 2001. 2003. Centers for Medicare and Medicaid Services unpublished data. http://www.cms.hhs.gov

Choi, H.K., 1993. Cultural and noncultural factors as determinants of caregiver burden for the impaired elderly in South Korea. Gerontologist, 33: 8-15. PMID: 8440505

Choi, M., 2004. Married Korean women's responses to domestic violence within the framework of sociocultural context. Unpublished doctoral dissertation, University of Arizona, Tucson, Arizona, ISBN: 978-0-4969-0531-7
Crist, J.D. and S. Escandón-Dominguez, 2003. Identifying, recruiting and sustaining Mexican American community partnerships. J. Transcul. Nurs., $\quad$ 14: $\quad 276-271 . \quad$ DOI: $10.1177 / 1043659603014003013$

Crist, J.D., 2002. Mexican American elders' use of skilled home care nursing services. Pub. Health Nurs., $\quad 19$ : $366-376 . \quad$ DOI: $10.1046 /$ j.15251446.2002.19506.x

Crist, J.D., 2005. The meaning for elders of receiving family care. J. Adv. Nurs., 49: 485-493. DOI: 10.1111/j.1365-2648.2004.03321.x

Crist, J.D., L.R. Phillips and D. García-Smith, 2006. Accommodating the stranger en casa: Mexican American elders' decisions to use home care services. Res. Theor. Nurs. Pract., 20: 109-125. DOI: $10.1891 / 088971806780641791$

Crist, J.D., S.H. Woo and M. Choi, 2007. A comparison of the use of home care services by AngloAmerican and Mexican American elders. J. Transcul. Nurs., 18: 339-348. DOI: $10.1177 / 1043659607305190$

Duffy, T.M. and D.J. Cunningham, 1996. Constructivism: Implications for the Design and Delivery of Instruction. In: Handbook of Research for Educational Communications and Technology, Jonassen, D.H. (Ed.). Simon and Schuster, Macmillan, New York, ISBN: 0-203-88086, pp: 177.

Elliott, S., J. Painter and S. Hudson, 2009. Living alone and fall risk factors in community-dwelling middle age and older adults. J. Commun. Health, 34: 301-310. DOI: $10.1007 / \mathrm{s} 10900-009-9152-\mathrm{x}$

Family Caregiver Alliance (FCA), 2007. Fact sheet: Selected caregiver statistics. http://www.caregiver.org/factsheets/caregiver_stats C.html

Faul, A.C., P.A. Yankeelov, N.L. Rowan, P. Gillette and L.D. Nicholas et al., 2009. Impact of geriatric assessment and self-management support on community-dwelling older adults with chronic illnesses. J. Gerontol. Soc. Work, 52: 230-249. DOI: 10.1080/01634370802609288

Fillenbaum, G.G., 1988. Multidimensional Functional Assessment of Older Adults: The Duke Older Americans Resources and Services Procedures. Lawrence Erlbaum, Hillsdale, NJ., ISBN: 978-08058-0241-2.

Gelfand, D.E., H. Balcazar, J. Parzuchowski and S. Lenox, 2001. Mexicans and care for the terminally ill: Family, hospice and the church. Am. J. Hospice Palliat. Care, 18: 391-396. DOI: $10.1177 / 104990910101800608$ 
Gure, T.R., M.U. Kabeto and K.M. Langa, 2009. The influence of long-term care insurance on the likelihood of nursing home admission. J. Am. Geriatr. Soc., 27: 1862-7. DOI: 10.1111/j.15325415.2009.02433.x

Hughes, L.C., N.A. Hodgson, P. Muller, L.A. Robinson and R. McCorkle, 2000. Information needs of elderly postsurgical cancer patient during the transition from hospital to home. J. Nurs. Scholar., 32: 25-30. DOI: $\quad 10.1111 / \mathrm{j} .1547-$ 5069.2000.00025.x

Jones, E.G., R.K. Mallinson, L.R. Phillips and Y. Kang, 2006. Challenges in language, culture and modality: Translating English measures into American sign language. Nurs. Res., 55: 75-81. PMID: 16601619

Kadushin, G. 2004. Home health care utilization: A review of the research for social work. Health Soc Work., 29: 219-44. PMID: 15453060

Kim, E. and B. Yang, 2005. Cost-effectiveness of longterm care services in South Korea. Arch. Gerontol. Geriatr., 40: 73-83. PMID: 15531025

Kim, E.H., 2007. The influence of culture on the experiences of Korean, Korean American and Caucasian-American family caregivers of frail older adults: A literature review. J. Korean Acad. Nurs., 37: 213-220. PMID: 17435406
Pol, L.G., K.J. Mueller and P.T. Adidam, 2002. Racial and ethnic differences in health insurance for the new elderly. J. Health Care Poor Underserv., 13: 229-240. PMID: 12017912

Robinson, H., 2001. Understanding internal consistency reliability estimates: A conceptual primer on coefficient alpha. Measur. Evaluat. Counsel. Dev., 34: 177-189.

Sabogal, F., G. Marín and R. Otero-Sabogal, 1987. Hispanic familism and acculturation: What changes and what doesn't? Hispanic J. Behav. Sci., 9: 397-412. DOI: 10.1177/07399863870094003

Tennstedt, S.L., M.L. Sullivan, J.B. McKinlay and R.B. D'Agostino, 1990. How important is functional status as a predictor of service use by older people? J. Aging Health, 4: 439-461. DOI: 10.1177/089826439000200402

US Census Bureau, 2007. Definition of disability differs by survey. http://www.census.gov/hhes/www/disability/disab_ defn.html

Wallace, S.P., L. Levy-Storms, R.S. Kington and R.M. Andersen, 1998. The persistence of race and ethnicity in the use of long-term care. J. Gerontol. Soc. Sci., 53: S104-S112. PMID: 9520935 